International Journal of Social Sciences Perspectives

ISSN: 2577-7750

Vol. 6, No. 2, pp. 59-67

2020

DOI: $10.33094 / 7.2017 .2020 .62 .59 .67$

(C) 2020 by the authors; licensee Online Academic Press, USA

\title{
Social Work Services for Persons with Disabilities in Nigeria: A Qualitative Inquiry
}

\author{
Solomon Amadasun
}

\section{Department of Social Work, Faculty of Social Sciences, University of Benin, Benin-City, Nigeria. \\ Email:amadasun.s@yahoo.com}

Licensed:

This work is licensed under a Creative Commons Attribution 4.0 License.

Keywords:

Social work

Persons with disability

Nigeria

Person-in-environment

Advocacy.

Accepted: 24 January 2020

Published: 6 February 2020

\begin{abstract}
The challenges experienced by persons with disabilities (PWDs) are real and profound, requiring the attention of social workers. Unless interventions are aimed at eliminating the broad range of societyimposed barriers, recovery efforts would continue to be undermined. The focus of this study is to share the experiences of social workers regarding their services to PWDs in Nigeria. Using a social constructivist theory, semi-structured interviews were conducted with social workers in one organization providing services to PWDs in Nigeria and the results were subjected to thematic analysis. Findings show that social work services provided to PWDs are inadequate in line with the person-inenvironment focus of the social work profession Application: While this research relates to practitioners in one organization, findings have broader implications for professionals and policymakers in Nigeria. In this regard, suggestions are offered to the Nigerian political leadership as well as to social work practitioners in order to ensure that comprehensive services are offered to this underserved and undervalued population.
\end{abstract}

Funding: This study received no specific financial support.

Competing Interests: The author declares that there are no conflicts of interests regarding the publication of this paper.

Acknowledgement: The author wishes to register his immense gratitude to the anonymous reviewers for their candid and constructive criticisms regarding the manuscripts, ultimately resulting in improvements of the final revision.

\section{Introduction}

The challenges experienced by persons with disabilities (hereinafter, PWDs) are real and profound, with social workers being at the frontline of providing support services to them. Until interventions that include the elimination of society-induced impediments are part of social workers' services, the goal of improving the social conditions of PWDs would continue to be a mirage especially in a context in which PWDs are undervalued and underserved. Although disability issues have continued to generate debates across Nigeria, often resulting in the unanimous recommendations from critical stakeholders for the enactment of disability laws that would ensure the protection of PWDs from all forms of social stereotype, stigma, and discrimination, as at the time of writing this paper, there is still no legal framework assuring their protection. PWDs in Nigeria are at the mercy of the whims of society's harmful values and beliefs, and adding to this barrier is the prevailing view of disability issues from a medical model. From this model, PWDs are considered as disease-infested people who require "cure" in order for them to get assimilated to mainstream society. The medical model centralizes victim-blaming while spotlighting charity as a means of assistance, thereby incapacitating PWDs all the more.

The National Population Commission (cited in Okogba (2018) reported that approximately 19 million people are currently living with some form of disability in Nigeria. While the medical model has dominated disability discourse in Nigeria, global trends have directed more attention to the social model of disability which considers the predicament of PWDs as contingent upon society's insensitivity and neglect. In drawing from the social model of disability, the United Nations Convention on the Rights of Persons with Disabilities (United Nations Conventions on the Rights of Persons with Disabilities (UNCRPD), 2006) defines PWDs as those who have long term physical, mental, sensory or intellectual impairments which in interaction with various barriers may hinder their full and effective participation in society on an equal basis with others (UNCRPD, 2006). 
Disability carries with it enormous consequences that, if left unattended, impacts on the psychological and social well-being of those affected. The challenges faced by PWDs are particularly dire in a hostile environment characterized by extreme poverty, limited education, poor social infrastructure, and discriminatory cultural values. In its Scoping Study, The Department for International Development (2015) identified the societal barriers faced by PWDs in Nigeria and group them into three distinct constituents: environmental, attitudinal, and institutional. The environmental aspect refers to the pervasiveness of incapacitating environmental facilities such as inaccessible public buildings, inaccessible transport system, lack of accessible information, and so on. Attitudinal barriers find expression in those unsubstantiated yet pervasive beliefs and ideas about the causes of disability, in which PWDs are viewed as justifiably suffering the consequences of their actions in their previous life. In this sense, disability is thus seen as an act of divine justice. Institutional barriers militating against the social inclusion of PWDs reflect in the lack of disability legislation, lack of formal social protection, and inaccessibility to mainstream public services such as education, health care, recreation etc. (Department for International Development (DFID), 2015). The challenges that abound in the daily lives of PWDs in Nigeria are purposely created and rooted in the structural fabric of the society. An internal report by the Leonard Cheshire Disability graphically summarizes the acute marginalization and social exclusion of PWDs in Nigeria:

'The abuses that disability communities face are such that they are contrary to [the] spirit of the Nigerian constitution, the African Charter on Human and Peoples Rights, the Convention Plan of Action for the African Decade of Persons with Disability, and the United Nations Convention on the Protection of the Rights and Dignity of Persons with Disability. They are often, treated as second-class citizens, shunned and segregated by physical barriers and social stereotypes. This discrimination occurs in a range of arena, including the workplace, schools, health centers, recreational facilities, and many more societal contexts. As a fall-out of social discrimination, economic marginalization, and a broad range of other human rights violations, people with disability face difficult challenges in living a normal life. To add salt to their injuries, they are ignored and sometimes excluded from development policies and programs. While some government and societies have adopted a social inclusion and rights-based approach to disability issues, Nigeria relies on charity models of assistance and a narrow medical model that focuses on finding medical "solution" to limitations caused by a disability and ignores the need to address the vast array of limitations created and imposed by discrimination, exclusion, ignorance, and a lack of access.' Leonard Cheshire Disability (2007).

In light of their challenges, several organizations provide social services to PWDs in Nigeria, with most of these organizations in the not-for-profit sector including both public and private organizations. Private organizations providing these services range from nongovernmental organizations (NGOs) to faith-based organizations (FBOs), civil society organizations (CSOs), and disabled people's organization (DPOs). The public establishment in charge of service delivery to PWDs in Nigeria is the Ministry of Women Affairs and Social Development within the federal and the various states government. Although different in their funding source, these organizations share a commitment of not only providing support for PWDs but also in utilizing the services of social workers who then draw from their expertise to provide support services to this highly undervalued people. In these organizations, social workers assume the lead position in the planning and execution of programs as well as being the primary service providers to PWDs. Although social workers have, over the years, been at the forefront in delivering social services to PWDs in Nigeria, the literature on the nature of social work services to PWDs in Nigeria is very limited. This study, in filling the gap in professional literature, therefore aims to examine the nature of social services provided to PWDs in Nigeria from the perspective of social workers. Understanding the nature of social work services to PWDs is crucial not only for evaluative purpose but also for the purpose of planning future interventions so that PWDs can have an improved social condition devoid of society-inflicted hurdles. Before proceeding to the research proper, it is necessary to ask: what is social work and what are its functions in society? This is especially important for readers in Nigeria who may not be too familiar with the tenets of the profession and what it represents for the society.

\section{What is Social Work?}

The social work profession carries with it a constellation of value, purpose, sanction, knowledge, and method put to action (Bartlett, 2003). Authoritatively, social work has been defined as a practice-based profession and an academic discipline that promotes social change and development, social cohesion, and the empowerment and liberation of people. Principles of social justice, human rights, collective responsibility and respect for diversities are central to social work. Underpinned by theories of social work, social sciences, humanities, and indigenous knowledge, social work engages people and structures to address life challenges and enhance well-being (International Federation of Social Work (IFSW), 2014). This definition has now become the gold standard in reference to the nature of the social work profession, with the aims, values, knowledge-based, and intervention-focus vividly highlighted.

The nature of social work services is such that it is comprehensive and broad as a result of the person-inenvironment (hereinafter, PIE) focus of the profession. The underlying principle of the PIE system is that interventions are aimed at restoring the social functioning of people while, simultaneously, working to improve social conditions so that people can be integrated into mainstream society. Improving social 
conditions connote eliminating environmental or institutional factors and/or barriers that contributed to the emergence of the problem, that aggravates the problem or that threatens to undermine people's recovery from the problem. It is the dual focus on people in their social and natural environment that separates social work from other helping professions and that make its intervention all-inclusive. As Greene (2009) wrote, "[ $\mathrm{t}]$ he person-in-environment perspective has been the central influence in the formation of the profession's knowledge base as well as its approach to practice' (p.1). This thought was echoed by Saari (1992) who uttered that 'it is quite possible that the person-in-environment perspective has been the single most characteristic and definitive element of social work practice from its beginnings' (p.205). The focus on people and their interaction with their environment has assumed a canonical status in the social work profession and ubiquitous in all aspects of social work interventions. Kemp (2001) found that the simultaneous commitment to person and environment is supported at all levels of the profession: in practice, in the professional literature, and in statements of the profession's purpose and mission' (p.7). In its Code of Ethics, the National Association of Social Work (NASW) highlighted these core principles of the social work profession in its preamble: 'to focus on individual well-being in a social context' and to 'promote social justice and social change with and on behalf of clients' (Preamble sec., paras. 1and 2). Specht and Courtney spelled-out the essential function of social work as 'concerned with helping people perform their normal life task... [and to] make use of and develop community and social resources to build connections with others and reduce alienation and isolation' (p.24). Weiss-Gal explains the central goal of the profession as to 'augment the ability of individuals, families, groups, and communities to solve their problems, realize their potential, and enhance their lives, while effecting social reforms intended to remove societal obstacles to the individual's well-being, to reduce inequality, and to increase social justice' (p.65). According to Kondrat (2002) the social work profession has long been at the vanguard of examining behavior from a holistic lens comparably with other helping professions. In emphasizing the common theme between the interaction of people and their environment, Karls and O'Keefe (2009) asserted that ' the uniqueness of social work among human service professions is its attention to the PIE perspective and its focus on enhancing the social functioning of people' (p.372).

The philosophical roots of the PIE perspective resonate with the six core values of social work (service, social justice, dignity and worth of the person, importance of the human relationship, integrity, and competence) and can be understood by inspecting Gordon's six concepts essential to social work practice:

1. The individual is the primary concern of this society.

2. That there is interdependence between individuals in the society.

3. They have a social responsibility to one another.

4. There are human needs common to each person, yet each person is essentially unique and different from others.

5. An essential attribute of a democratic society is the realization of the full potential of each individual and the assumption of his social responsibility through active participation in society.

6. Society has a responsibility to provide ways in which obstacles to this self-realization (that is, the disequilibrium between the individual and his environment) can be overcome and prevented (Gordon, $1965)$.

On the whole, the nature of social work services is summed up in the endeavor to get the broadest possible understanding of service-users' situations by reviewing the causes of their problems from where services are then directed towards (a) rehabilitating their cognitive functioning from the lens of their inherent strengths as this is cardinal to their immediate recovery, (b) restoring their social functioning from a developmental paradigm as this is integral to their long-term recovery and adjustments to mainstream society, and (c) working to prevent the re-emergence of the problem. All of these underscore the fact that the nature of social work services is premised on a philosophical foundation that is rehabilitative or curative (micro/mezzo-focused), developmental and structural (macro-focused), and preventive (micro, mezzo, and macro).

\section{Theoretical Framework}

The social work profession has evolved from a field that relies on other professions to develop social constructs and theories to one that has started to develop its own unique constructs that solely rely on an intricate interplay and understanding between people and their social environment (Cooper, 2001). As a corollary to the above, social constructivist theory was utilized to guide the theoretical framework in this study. As Cooper (2001) explains, 'the central goal in using constructivism in research [is] to study the social processes that people use to describe and understand their world' (p.721). Thus, constructivism was used to explore the perceptions of social workers' regarding the nature of their services to persons with disabilities which is informed by their active engagement with this population. According to Hoffman (1990) the interaction between social workers and their working environment is largely determined by their ideas and views about certain social phenomenon. Using social constructivist theory in a social work inquiry involves the researcher taking a position of curiosity with the study participants by using language to attempt to 
understand participants' reality while also recognizing that no two study participants have the same view about a given phenomenon despite living through similar experiences.

\section{Method}

\subsection{Sample and Procedure}

The participants in this study are practicing social workers who were working in one major not-for-profit organization that is committed to providing services to PWDs southern Nigeria. The organization is mid-size with shelters and a large space for PWDs. While non-restrictive, women and children are the major PWDs in the organization. The participants were purposively selected and they occupied executive and administrative positions in the organization. Since the researcher was the field liaison to the organization, securing the consent of the social workers to participate in this study was not so much daunting. All the participants were qualified social workers who had a minimum of a bachelor's degree in social work. In May 2018 when the idea of this study was first conceived, the participants were informed about the objective of the study of which nine of the ten prospective social workers approached had given their consent to participate in the study. However, as at the time of commencing the interview in the following month, two of the nine volunteering participants had opted out. Thus, the total sample size was reduced to seven (i.e., 5 female and 2 male) participants.

\subsection{Data Collection and Analysis}

This study employed a qualitative research approach and a semi-structured interview schedule based on one-on-one interviews with the participants served as the means of data collection. The interviews lasted a duration of 45 to 60 minutes each and were audio-recorded and transcribed. The process of thematic content analysis was utilized in analyzing the data from the interviews. The steps as suggested by Terre-Blanche, Durrheim, and Kelly (2006) was followed in the course of the data analysis. These include: (a) familiarization and immersion, (b) inducing theme, (c) coding, (d) elaboration, and (e) interpretation and checking. To ensure the validity of the qualitative data, Maxwell's five validity categorization in qualitative research was used (Maxwell, 2008). Descriptive validity is based on an attempt to accurately describe the data by means of transcripts of verbatim responses. In this regard, no information was left out or altered and the use of an integrated independent coder also contributed to descriptive validity. Interpretive validity was ensured by the use of the transcript that included both the verbal and non-verbal data to justify interpretations. The use of purposive sampling technique and a thorough description of the implementation of the research methodology ensured the transferability of the findings to other similar contexts. To ensure theoretical validity, a literature control was done once the themes and sub-themes were identified through data analysis. Evaluative validity was achieved by ensuring that the evaluation was based on the findings that emanated from the process of data analysis.

\subsection{Ethical Considerations}

The ethical issues addressed in this study were informed consent, voluntary participation, privacy, and protection from harm. Accordingly, identifying details of the study participants and their organization is concealed. To further obscure individual identification, their responses are presented as a collective story.

\section{Discussion of Findings}

Three themes (see Table 1) emerged during the course of the data analysis: the importance of social work services, the nature of social work services, and the challenges to effective service delivery. The result is presented based on the themes that emerged from the qualitative analysis and are illustrated with verbatim responses of the participants (identified by their status and gender), and followed by a literature control.

Table-1.Thematic framework of the result.

\begin{tabular}{l|l}
\hline \multicolumn{1}{l}{ Theme } & Subtheme \\
\hline \multicolumn{1}{l}{ The importance of social work services } \\
\hline The nature of social work services & Rehabilitation-focused services \\
\hline Barriers to effective service delivery & Insufficient resources \\
\hline & Shortage of social workers \\
\hline & Lack of training programs \\
\hline & Lack of professionalization \\
\hline & Poor remuneration \\
\hline
\end{tabular}

Theme 1: The Importance of Social Work Services

In explaining the hostilities faced by PWDs and the fact that most families do not want to associate with their physically challenged, the participants underscored the imperative of providing social services. One participant stated: 
It is unimaginable what would happen to PWDs if social work services are not readily available. Who would look after them? Is it their family members that are ashamed of them and that exclude them from the public that would do so? In precolonial times, yes, but today, things have changed and so without the help of service providers, PWDs would be left to the streets as many are by the way. (Social worker, female).

Also, in highlighting the breakdown of the traditional support system, the participants spoke glowingly of the importance of providing services to PWDs:

Some families still look after for their disabled relations in the villages but, due to the harsh economy, many of them are experiencing challenges and dumping their disabled in the cities. Speaking from experience, that is the reality. So if social workers are not on the ground to cater for these people, who would do so. Clearly, the essentiality of social services cannot be overemphasized. (Social worker, female).

Akhihiero (2011) discussed how the collapse of the traditional support system in Africa has resulted in the neglect of PWDs as a result of globalization and neoliberal economic policies. According to him, PWDs who hitherto would have been catered for by the kinship system are now living on the fringe, dejected and isolated and often without hope. Iyabo (2014) found that PWDs are often abandoned and abused by their relations, noting that their precarious situation requires urgent attention from social service providers.

\section{Theme 2: The Nature of Social Work Services}

The participants highlighted the nature of their services as comprising of rehabilitation services such as conducting counseling and organizing recreational activities. Furthermore, in acknowledging the importance of education and empowerment programs in improving the living conditions of PWDs, the participants, however, noted that such services had long been abandoned:

Basically, we provide a wide range of services that are important to PWDs. What we mainly do is to, first of all, ensure that they are rehabilitated because of the open stigma and aspersions that have been cast on them even from their relatives and so we make sure they are in a stable mental state. (Social worker, female).

They received recreational and counseling service where they are informed that they are not disabled as the society want them to believe but instead they are led to believe that they have strengths. Because of this, many of them took vocational courses where they learned different skills and crafts but today, this is no longer available and they have been dejected by it and this troubles us. (Social worker, female).

Akhihiero (2011) affirmed that PWDs have continued to suffer systemic neglect owing to the collapse of the previously existing vocational and educational centers for PWDs across the country. He stated that unless such vital services are restored, challenges accompanying disability issues would continue. Due to the hostile attitudes that have been directed at PWDs which then affect their mental well-being, providing counseling services is crucial (Iyabo, 2014).

Given that this was the main research question, the social workers were requested to discuss what they had done in the face of the glaring abandonment of such essential services for PWDs. Their responses were characterized by the expression of doubt regarding whether or not it was their responsibility to advocate for the revival of such services. Also, they sought clarity regarding how they would go about this task in the event that they were convinced that this was within the purview of the social work profession:

It is very displeasing that this has become the reality but can we do in this situation? Don't forget that our organization is non-governmental. Although there was a partnership between the government's women affairs and social development ministry and our organization but such partnership have not improved the fortunes of PWDs as there are no funds from the government. (Social worker, male).

Let pretend that this something we can do... can we just go the ministry and carry placards by way of organizing a protest or what? Look, this is something that social workers are not paid to do... we hope one day that the government will also reverse their policy and bring back this vital and empowering services (Social worker, female).

In her article, "Exploring a New Direction for Social Work Education and Practice in Nigeria", Anucha (2008) enunciated the nature of social work education in Nigeria, having been designed along the British and American remedial model and with an overwhelming emphasis on casework or individual practice, has profoundly limited the capacity of social workers to assert their influence in the public arena. Thus, issues affecting PWDs from the policy realm are, at best, met with role confusion for social workers or, at worst, typified by outright denial.

In any given contexts, the goals of social workers in their working relationship with service users are clearly defined accompanied by efforts aimed at achieving it. The participants spoke of their goal with PWDs as restoring their capacity to effectively function in society without any forms of discrimination and denial of services. This goal is suggestive of the importance of public and policy advocacy given that the public is the major drivers of such stigmatizing and discriminatory practice and that the denial of essential empowering services is rooted in the policy process (Mmatli, 2009). Thus, the participants were probed as to whether or not they were prepared to engage in public and policy advocacy, while they welcomed the idea, they equally uttered that their roles were ultimately agency-determined and that they could not overstep such boundary:

Through recreational and rehabilitative services, our goal is to ensure that PWDs become functional in society. This is our ultimate commitment and this is what we would love to see happen. (Social worker, male). 
Yes, this is a great suggestion. We would love a situation where some of us would take up such a role, but who will? We would love to see that PWDs are empowered again through vocational education and skill learning programs but we cannot force the government. This is an NGO and we work according to our job specifications unless you want to have problems we the directors. (Social worker, female).

Jordan (2004) explained that social workers rather than being agents of social change by means of liberating people from their predicaments have now become agents of social control. Through this role, they act on the whims of their organizations even when such agency policy may not ultimately bode well for the long term benefits of their service users. To this end, in order to stay true to the profession's historic value commitment, social workers must embrace their primary responsibility of promoting social change (Jordan, 2004) through the instrument of policy advocacy.

\section{Theme 3: Barriers to Service Delivery}

The participants pointed out several issues as impediments to their service delivery. These include insufficient resources, shortage of social workers, lack of regular training, non-professionalization, and poor remuneration.

Theme 3.1: Insufficient Resources

The participants described how the lack of sufficient resources has limited their capacities to make a meaningful impact in the lives of PWDs. They noted the high cost of providing care for PWDs, insisting that without adequate funding, the impact of their services would wane:

Caregiving is costly because, in this day and age, without finance, it is always difficult to implement programs and services. How is it even possible to maximum impact on the lives of people whose situation require proper care and planning with no funds? (Social worker, female).

The government has failed woefully in making funds available for PWDs and nongovernmental organization can only do so little against the background that they have limited resources and human capacity as well as the fact that government subventions are never sufficient to cater for PWDs. (Social worker, male).

Rekart (1993) observed how the impact of globalization and neoliberal economic policies have affected the not-for-profit organizations thereby limiting the scope and effectiveness of their services. According to her, neoliberal policies have undermined the delivery of social welfare services to vulnerable populations, in which case the third sector who had been the major proponent of social service delivery have had their capacities limited. To offset such deficit, she advocated for subventions in order to enable them to keep up with their services amidst the deliberately-triggered austerity.

Theme 3.2: Shortage of Social Workers

In their discussion of the dearth of social workers in affecting their work, the participants noted that there are wide margins in relation to the number of social workers working with PWDs. They posited that with such high caseloads, it was inevitable that their services would not operate at an optimal level:

There is no way we can be able to operate to the fullest level when there is a shortage of human personnel who have the capacity to provide adequate care. If more social workers are not employed, who will now provide support to PWDs? Do you know the ratio of social workers to PWDs in our organization for example and do you realize the severity of this shortage? For your information, we have one social worker attending to twenty-six physically challenged persons in our organizations and the number of social workers we have here is laughable compared to the number of PWDs. (Social worker, female).

Who is deceiving who? Agencies have overstretched capacity but the government that has the capacity don't want to employ more social workers. They can employ more and then contract these professionals to NGOs maybe through a memorandum of understanding or something since NGOs are the only ones committed to providing services to PWDs. (Social worker, female).

According to the Social Work Policy Institute (2010) high caseloads burden social workers as it not only leads to depression and burn-out in their daily encounter but also undermines the effectiveness of their services. Idyorough (2013) explained that one of the issues affecting service delivery to vulnerable populations such as PWDs is the shortage of social work practitioners in Nigeria.

\section{Theme 3.3: Lack of Retraining Programs}

The participant, in recognizing the dynamic nature of the social work profession, identified lack of retraining programs as hampering their capacity to provide enhanced services to PWDs. They stated that through regular training programs, they would be better positioned to make significant contributions. However, they spoke of training programs as not exclusive to the classroom but that training should be organized in the form of symposiums and in the publication of evidence-based and contextually-relevant research, from where they can add to their knowledge and their practice would be guided:

Times are changing and so what you know yesterday may quickly become obsolete today... and for this not to happen, professionals need to sharpen their skills so that they will be abreast of current happenings within their field of endeavor... where they can learn something new to become more responsive, effective, and efficient. And all of this 
requires constant training but have we have this experience to learn more, none that my memory can remember. (Social worker, male).

Training programs are essential for effective services for the benefit of PWDs but we have not benefited from this platform. For example, the ministry of women affairs and social development can collaborate with NGOs to organize training programs for professionals providing services for PWDs and this does not have to be going back to school as that may be too costly. My point is, providing care for PWDs requires joint efforts among public and private organizations and should not be left for social workers in NGOs alone and in order for this not to be the case, social workers need to constantly hone their skills by way of training which is currently not available. (Social worker, female).

Malmberg-Heimonen (2015) wrote that the nature of social work is such that require consistent education and retraining among its professionals so that they would be able to provide efficient and effective services that are in line with current research findings and with the best practice standards. Scholars such as (Anucha, 2008; Idyorough, 2013) affirmed that the irregular training of social workers has contributed to their inability to deliver quality service to vulnerable groups in Nigeria.

\section{Theme 3.4: Lack of Professionalization}

That the social work profession has not been given statutory recognition by the Nigerian government was also discussed as a major bane to effective service delivery to PWDs. The participants vehemently avowed that if the profession had been legalized, that would have given them the legal impetus to go the extra mile in ensuring that PWDs are adequately provided with the necessary resources to lead a normal life:

The issue of professionalization is a very thorny one because there seems to be this conspiracy among government officials that we will bring them to their knees if social work is legalized. The government knows we can do this and so are doing all they can to prevent the professionalization process and this situation has dampened our morale tremendously. (Social worker, female).

Can you imagine what could happen if social work gets that legal backing? With that, we can challenge the authorities to make sure that they provide the resources to PWDs because as things are right now, their situation is nothing to write home about. So with professionalization, we would be enabled to organize a protest or even go on industrial action until the needs of PWDs are met. (Social worker, male).

Although there is no consensus in the literature, the issue of professionalization has been considered has paramount to effective service delivery. According to Thompson (2012) the less professional social work is, the less valued services would become resulting in low morale among practitioners. This remark echoes the observation made by Idyorough (2013) who noted that the lack of professionalization has affected the morale of social workers but not on the scale in which it has negatively impacted vulnerable people.

\section{Theme 3.5: Poor Remuneration}

Although in a rather subtle tone, social workers believed that their poor remuneration side-by-side with other helping professionals combined with their long hours and commitment to PWDs was a limiting factor inhibiting their services:

We will keep doing what we can to ensure that PWDs are living their dreams even though not to their fullest but at least in a way that can bring them some moment of happiness because that is what they deserve. And even though this means that we will continue to receive peanuts as long as our service users who are our responsibilities are happy, we will also be happy because their joy is limitless and cannot be fully expressed. All you need to do is to witness it. (Social worker, female).

Social workers are driven by an unmatched passion and commitment for service to vulnerable people in particular and to society as a whole. In their altruistic act, they suppress their own interests while prioritizing the needs and interests of PWDs. Such altruism stems from the National Association of Social Work (NASW) Code of Ethics which averred that the primary goal of social workers is to help people in need and to address social problems' (National Association of Social Workers (2008) ethical principles section, para.2.)

\section{Limitations of the Study}

This study is limited in that, as qualitative research, its findings are not generalizable. Also, that the study focused only on social workers in a nongovernmental organization limited this study in that, if the views of social workers in the public sector were included, the findings might have been different in addition to offering a balanced insight. However, since there is no specialized public organization committed to providing services to PWDs in Nigeria, this study had to engage the perceptions of social workers in NGOs as they are the ones working in this regard. These limitations notwithstanding, this study has set the groundwork for future discussions and evaluation of the nature of social work services to PWDs in the country.

\section{Recommendations and Conclusion}

Findings of the interviews have confirmed that social workers' services to PWDs are, first and foremost, inadequate in line with the person-in-environment focus of the social work profession and that, secondly, they are confronted with enormous challenges which may account for their lopsided services. Granted that they are 
faced with significant challenges, more could still be done towards improving services for PWDs, given that social workers have historically made available the best of services during the worst of times (Jordan, 2004). In light of the structural dimension of the barriers hampering social work services, the following recommendations are not only directed to social workers but also, and perhaps most importantly, to the Nigerian political leadership.

\subsection{Suggestions for Social Workers}

1. Social workers, while continuing their current services, should endeavor to frame their services from a rights-based perspective. This entails mainstreaming the rights of PWDs so that efforts aimed at responding to disability issues would not be seen as a privilege but as a right.

2. Social workers should advocate for resources necessary for the empowerment of PWDs.

3. Social workers should expedite action towards enlightening families, relatives, and communities about the causes of disabilities with the aim of eliminating all forms of stigmatizing and discriminatory practices directed at PWDs.

4. Social workers must recognize the impact of the lack of legislation on the well-being of PWDs and, as such, advocate for laws that would ensure the protection of PWDs in the country.

5. Improving the social conditions of PWDs require a collective effort among key stakeholders. Thus, social workers should work closely with other stakeholders in their quest towards restoring the social functioning of PWDs.

\subsection{Suggestions to the Nigerian Government}

The Nigerian constitution is clear about the responsibility of the political leadership in ensuring the protection of the citizens of Nigeria regardless of whether or not they are disabled or able-bodied. To this end, the Nigerian government should, as a matter of accountability, act as follows:

1. Commit resources to provide support to PWDs.

2. Create a special unit within the Ministry of Women Affairs and Social Development that would be dedicated to disability issues in Nigeria.

3. Expedite action towards the professionalization of social work in the country.

4. Take drastic measures towards the employment of social workers and then subcontracting these practitioners to frontline organizations who lack the resources to engage their expert services.

5. Create an enabling environment that promotes knowledge acquisition and sharing among stakeholders in which practitioners in non-governmental organizations would be beneficiaries. This could be achieved through a public-private partnership between the government, and social work educators and researchers who would then enlighten social workers on current best practice standards.

6. Provide subventions to frontline organizations that are committed to providing support services to PWDs to enable them to surmount their resource challenges.

7. Set in motion a legal framework that not only guarantees the protection of PWDs from stereotype and all forms of harmful practices but that also mainstream disability issues from a rights-based perspective.

\subsection{Suggestions for Future Research}

Since this is an exploratory-descriptive study, suffice to say that more research is conducted on this subject with a view to expanding the literature so that social workers in the country would have a stream of evidence-based knowledge to draw from in their service delivery to PWDs in Nigeria. Future research could concentrate on the evaluation of the role of social workers in working with PWDs in Nigeria in order to identify gaps for the purpose of improving interventions. Additionally, research may also focus on examining factors that influence social workers' commitment to providing services to this undervalued population in the face of limited resources and lack of statutory professional recognition. These are, to name but a few, future research considerations for social work professionals (researchers, educators, practitioners, and even student social workers) in Nigeria.

\subsection{Closing Remarks}

In exploring the nature of social work services to PWDs, it is argued that unless services are tailored to meet the broad needs of PWDs, following the person-in-environment perspective of the social work profession, any efforts aimed at one aspect of the PIE system would continue to yield sub-optimal impact and, thus, inadequate. Findings of this study show that the nature of social workers' services to PWDs are insufficient given the enormity of the experiences of disabled persons in Nigeria. In addition, it is also revealed that social workers themselves undergo numerous challenges hampering their delivery of effective services to this population. However, there is every reason to believe that social workers, when given the right resources and incentives from their organizations and especially from the Nigerian government, have the ability to 
provide comprehensive services that would not only meet the immediate needs of PWDs but that would ensure their restoration to and social functioning in mainstream society.

\section{References}

Akhihiero, P. A. (2011). Mainstreaming persons with disabilities in the vision 2020 agenda: A call for the enforcement of their social, economic, and political rights. Paper presented at the A Lecture Delivered at the 1st NAPVID“ Right Bbove Charity" Lecture to Mark the International Day for People With Disabilities, Held in Benin-City, December 2nd.

Anucha, U. (2008). Exploring a new direction for social work education and training in Nigeria. Social Work Education, 27(3), 229-242. Available at: https://doi.org/10.1080/02615470701381459.

Bartlett, H. M. (2003). Working definition of social work practice. Research on Social Work Practice, 13(3), $267-270$. Available at: https://doi.org/10.1177/1049731503013003011.

Cooper, B. (2001). Constructivism in social work: Towards a participative practice viability. British Journal of Social Work, 31(5), 721-738. Available at: https://doi.org/10.1093/bjsw/31.5.721.

Department for International Development (DFID). (2015). Scoping study: Disability issues in Nigeria. Abuja, Nigeria: Author.

Gordon, W. E. (1965). Knowledge and value: Their distinction and relationship in clarifying social work practice. Social Work, 10(3), 32-39. Available at: https://doi.org/10.1093/sw/10.3.32.

Greene, R. (2009). Human behavior theory, person-in-environment, and social work method. In Greene, R.R. (Eds.), Human behavior and social work practice (2nd ed.). New Brunswick, NJ: Transaction Publishers.

Hoffman, L. (1990). Constructing realities: An art of ienses. Family Process, 29(1), 1-12. Available at: https://doi.org/10.1111/j.1545-5300.1990.00001.x.

Idyorough, A. E. (2013). Social work administration in Nigeria: Challenges and prospects. Paper presented at the A Lecture Delivered in Abuja Under the Auspices of the Nigerian Association of Social Workers (NASoW), March, 26th and 27 th.

International Federation of Social Work (IFSW). (2014). The global definition of the social work profession. Retrieved from: http://www.ifsw.org/what-is-social-work/global-definition-of-social-work/.

Iyabo, O. M. (2014). Parental attitude towards disability and gender in the Nigerian context: Implications for counseling. Mediterranean Journal of Social Sciences, 5(20), 2255-2260.

Jordan, B. (2004). Emancipatory social work? Opportunity or oxymoron. British Journal of Social Work, 34(1), 5-19. Available at: https://doi.org/10.1093/bjsw/bchoo2.

Karls, J., \& O’Keefe, M. (2009). Person-in-environment system'. In Roberts, A.R. (Eds.), Social workers' desk reference. New York: Oxford University Press.

Kemp, S. P. (2001). Environment through a gendered lens: From person-in-environment to woman-in-environment. Affilia, 16(1), 7-30. Available at: https://doi.org/10.1177/08861090122094118.

Kondrat, M. E. (2002). Actor-centered social work: Re-visioning "person-in-environment" through a critical theory lens. Social Work, 47(4), 435-448. Available at: https://doi.org/10.1093/sw/47.4.435.

Leonard Cheshire Disability. (2007). Three-year strategic plan for Nigeria. London: Author.

Malmberg-Heimonen, I. E. (2015). Social workers' training evaluated by a cluster-randomized study: Reemployment for welfare recipients? Research on Social Work Practice, 25(6), 643-653. Available at: https://doi.org/10.1177/1049731515569357.

Maxwell, J. A. (2008). Qualitative research design: an interactive approach (3rd ed.). Thousand Oaks: Sage Publications.

Mmatli, T. O. (2009). Translating disability-related research into evidence-based advocacy: The role of people with disabilities. Disability and Rehabilitation, 31(1), 14-22. Available at: https://doi.org/10.1080/09638280802280387.

National Association of Social Workers. (2008). NASW code of ethics. Washington, DC: Author. Retrieved from: http://www.naswdc.org/pubs/code/code.asp.

Okogba, E. (2018). NPC puts Nigeria's disabled population at 19 million. The Vanguard. Retrieved from: http://www.vangaurdngr.com/2018/10/npc-puts-nigerias-disabled-population-at-19million/.

Rekart, J. (1993). Public funds, private provisions: The role of the voluntary sector. Vancouver: University of British Columbia Press.

Saari, C. (1992). The person-in-environment reconsidered: New theoretical bridges. Child and Adolescent Social Work Journal, 9(3), 205-2 19. Available at: https://doi.org/10.1007/bfo0755861.

Social Work Policy Institute. (2010). High caseloads: How do they impact delivery of health and human services? Research to Practice Brief. Retrieved from: http://www.socialworkpolicy.org/wp-content/uploads/2010/02/r2p-cwcaseload-swpi-1-10.pdf.

Terre-Blanche, M., Durrheim, K., \& Kelly, K. (2006). First steps in qualitative data analysis. In Terre-Blanche, M., Durrheim, K. and Painter, D. (Eds.) Research in practice: Applied methods for the social sciences (2nd ed., pp. 320-344). Cape Town: University of Cape Town Press.

Thompson, N. (2012). Why we must reaffirm professionalism in social work. The Guardian, April 23. Retrieved from: http://www.theguardian.com/social-care-network/2012/april/23/professional-development-work-practices/.

United Nations Conventions on the Rights of Persons with Disabilities (UNCRPD). (2006). Disabilities convention. Geneva, Switzerland: Author. 